\title{
PENGARUH PENGGUNAAN LAMPU BAWAH AIR (UNDERWATER LAMP) TERHADAP HASIL TANGKAPAN BAGAN PERAHU (BOAT LIFT NET) DI PELABUHAN PERIKANAN NUSANTARA (PPN) KARANGANTU KOTA SERANG
}

\author{
Effect of Underwater Lamp Usage on Boat Lift Net Fishing Catch at Karangantu Fishing Port Serang City
}

\author{
Aditya Nuraga, Bogi Budi Jayanto, Indradi Setiyanto \\ Departemen Perikanan Tangkap, Jurusan Perikanan, \\ Fakultas Perikanan dan Ilmu Kelautan, Universitas Diponegoro \\ Jl. Prof. Sudarto, SH, Tembalang, Semarang, Jawa Tengah - 50275, Telp/Fax. +6224 7474698 \\ Email: nuragaaditya@gmail.com
}

Diserahkan tanggal 26 Juli 2018, Diterima tanggal 15 Agustus 2018

\begin{abstract}
ABSTRAK
Bagan perahu merupakan salah satu jenis alat tangkap di PPN Karangantu yang beroperasi pada malam hari. Bagan perahu menarik ikan target tangkapan yaitu ikan pelagis kecil fototaksis positif menggunakan atraktor cahaya berupa lampu. Salah satu kendala nelayan bagan perahu adalah pencahayaan lampu mengalami pembiasan. Penggunaan lampu bawah air bertujuan untuk mengurangi pembiasan. Tujuan dari penelitian ini adalah mengetahui pengaruh penggunaan lampu bawah air terhadap hasil tangkapan bagan perahu dan mengetahui komposisi hasil tangkapan bagan perahu dengan dan tanpa lampu bawah air. Penelitian ini dilakukan selama 10 trip menggunakan metode experimental fishing. Selisih berat total hasil tangkapan antara bagan perahu dengan dan tanpa lampu bawah air pada trip 1 sebesar 33,4 kg, trip 2 sebesar 38,9 kg, trip 3 sebesar 31,1 kg, trip 4 sebesar 41,1 kg, trip 5 sebesar $28,8 \mathrm{~kg}$, trip 6 sebesar $30,5 \mathrm{~kg}$, trip 7 sebesar $35,4 \mathrm{~kg}$, trip 8 sebesar $34,3 \mathrm{~kg}$, trip 9 sebesar $38,7 \mathrm{~kg}$ dan trip 10 sebesar $31,6 \mathrm{~kg}$ sehingga menunjukkan hasil tangkapan lebih banyak bagan perahu dengan lampu bawah air. Hasil tangkapan utama bagan perahu adalah ikan Teri (Stolephorus sp.) dan Cumi-cumi (Loligo sp.). Hasil tangkapan sampingan bagan perahu antara lain ikan Petek (Leiognathus sp.), Tembang (Sardinella sp.), Lemuru (Amblygaster sirm), Selar Kuning (Selaroides leptolepi) dan Layur (Lepturacanthus savala). Kesimpulan yang dapat diambil yaitu terdapat pengaruh antara lampu bawah air dengan hasil tangkapan pada bagan perahu.
\end{abstract}

Kata kunci: Karangantu, Lampu bawah air, Bagan perahu, Hasil tangkapan

\section{ABSTRACT}

Boat lift net is one type of fishing gear at PPN Karangantu which operates at night. Boat lift net attracts the target catch fish, the small pelagic fish is positive phototaxis using a light attractor in the form of a lamp. One of the constraints of fishermen on the boat chart is that the lighting has experienced refraction. Underwater lamp aims to reduce refraction. The purpose of this research is to know the effect of underwater lamp usage on boat lift net fishing catch and to know the composition of boat lift net with and without using underwater lamp. This research was conducted for 10 trips using experimental fishing methods. The difference in total catch of boat lift net with and without underwater lamp on trip 1 is 33,4 kg, trip 2 is 38,9 kg, trip 3 is 31,1 kg, trip 4 is $41,1 \mathrm{~kg}$, trip 5 is 28,8 $\mathrm{kg}$, trip 6 is 30,5 kg, trip 7 is 35,4 kg, trip 8 is 34,3 kg, trip 9 is 38,7 kg and trip 10 is 31,6 kg so it shows the catch is more the boat lift net with underwater lamp. Fish targets of the boat lift net are Anchovy (Stolephorus sp.) and Cuttlefish (Loligo sp.). The bycatches of boat lift net are Pony fish (Leiognathus sp.), Fringescale sardinella (Sardinella sp.), Indian sardinella (Amblygaster sirm), Trevally (Selaroides leptolepi) and Hairtail fish (Lepturacanthus savala). The conclusion that can be drawn that there is an influence between underwater lamp and catches on the boat lift net.

Keywords: Karangantu, Underwater lamp, Boat lift net, Fishing catches

\section{PENDAHULUAN}

Kota Serang berbatasan langsung dengan laut menyebabkan salah satu sumber pendapatan ekonomi daerah yaitu mengandalkan produksi perikanan dan memanfaatkan hasil penangkapan ikan. PPN Karangantu menjadi pusat kegiatan perikanan di Kota Serang. Produksi ikan hasil tangkapan yang didaratkan di memiliki peran penting dalam meningkatkan kondisi ekonomi masyarakat sekitar. Nelayan di PPN Karangantu banyak menggunakan bagan perahu karena hasil tangkapannya yang melimpah. Bagan perahu adalah alat tangkap pasif beroperasi pada malam hari menggunakan cahaya lampu untuk menarik ikan sasaran yaitu ikan pelagis kecil fototaksis positif. Menurut Rahmawati et al. (2017), Bagan perahu lebih efektif menangkap ikan pelagis dibandingkan dengan payang, pancing, gillnet dan alat tangkap lainnya. Pengoperasian yang menggunakan perahu menjadikan daerah penangkapan bagan perahu lebih luas. Selain itu, banyaknya nelayan di sekitar PPN Karangantu memilih menggunakan bagan perahu karena hasil tangkapannya dianggap lebih melimpah dibanding alat tangkap lain.

(C) Copyright by Saintek Perikanan (Indonesian Journal of Fisheries Science and Technology), ISSN : 1858-4748 
Produktivitas hasil tangkapan pada bagan perahu dapat ditingkatkan dengan menambahkan lampu bawah air sehingga pencahayaan tidak mengalami pembiasan dan pemantulan oleh permukaan air. Hasil tangkapan lampu bawah air secara keseluruhan lebih banyak dibandingkan dengan hasil tangkapan dengan lampu petromak (Fuad et al., 2016). Cahaya yang masuk ke dalam perairan menjadi sedikit karena adanya pemantulan dan bahkan sinar yang dihasilkan tidak stabil yang pada gilirannya tidak memberikan hasil tangkapan yang memuaskan bagi nelayan. Oleh karena itu dibutuhkan suatu sumber cahaya yang lebih efektif untuk menarik perhatian ikan dan mampu mengumpulkan ikan. Salah satu cara untuk mengurangi efek pemantulan dan tidak stabilnya cahaya lampu adalah dengan cara memasukkannya ke dalam air. Lampu yang dipakai adalah lampu listrik yang dirakit agar kedap air (Brown et al., 2013). Jika sebuah lampu dipasang diatas permukaan air hanya separuh saja cahaya yang dapat efektif menembus ke dalam air akibat dari adanya pemantulan permukaan air (BBPPI, 2012).

Bagan perahu (boat lift net) merupakan alat tangkap pasif yang operasinya dilakukan pada malam hari dengan menggunakan cahaya lampu sebagai atraktor untuk menarik ikan. Sasaran utama dari bagan perahu adalah ikan pelagis kecil dan ikan bersifat fototaksis positif seperti ikan Teri (Stolephorus sp.) dan Cumi-cumi (Loligo sp.). Bagan perahu juga sering mendapatkan hasil tangkapan sampingan seperti ikan Layur (Trichulus sp.), Tembang (Sardinella sp.), Pepetek (Leiognathus sp.) dan ikan lainnya. Menurut Bahri (2008), hasil tangkapan bagan perahu pada umumnya adalah ikan pelagis kecil seperti ikan Tembang (Clupea sp.), ikan Teri (Stolephorus sp.), ikan Japuh (Dussumiera sp.), ikan Selar (Charanx sp.), ikan Pepetek (Leiognathus sp.), ikan Kerotkerot (Therapon sp.), Cumi-cumi (Loligo sp.), Sotong (Sepia sp.), ikan Layur (Trichiurus sp.) dan ikan Kembung (Rastrelliger sp.)

Permasalahan yang sering dialami nelayan tentang aplikasi teknologi lampu karena pembiasan cahaya dari penggunaan lampu permukaam. Pencahayaan lampu permukaan tidak seluruhnya masuk dalam air namun dipantulkan lagi oleh permukaan air, oleh karena itu dimanfaatkannya teknologi lampu bawah air untuk mengurangi buruknya efek penyinaran lampu permukaan. Kondisi perairan seperti gelombang dan tingkat kejernihan menentukan baik buruknya efek penyinaran. Penggunaan lampu bawah air diharapkan cahaya masuk seluruhnya dalam air sehingga cahaya yang dihasilkan lebih optimal dan hasil tangkapan pun akan bertambah. Menurut Yulianto et al. (2014), para peneliti mulai mengembangkan lampu bawah air untuk mengurangi besar penurunan nilai iluminasi yang disebabkan oleh pemudaran akibat perbedaan media rambat cahaya dan mengurangi pemborosan energi untuk penggunaan lampu sebagai alat bantu penangkapan. Pengembangan tersebut melalui penggunaan langsung lampu bawah air sehingga tidak terjadi lagi suatu pembiasan maupun pembelokan cahaya. Kondisi ini diharapkan penggunaan besar sumber cahaya akan lebih efektif dan efisien. Teknologi lacuba sudah diketahui penggunaannya, yaitu sejak tahun 1990-an. Tujuan pelaksanaan penelitian adalah mengetahui pengaruh penggunaan lampu bawah air (underwater lamp) terhadap hasil tangkapan bagan perahu (boat lift net) serta mengetahui komposisi hasil tangkapan antara bagan perahu (boat lift net) dengan menggunakan lampu bawah air (underwater lamp) dan bagan perahu (boat lift net) tanpa menggunakan lampu bawah air (underwater lamp) di Pelabuhan Perikanan Nusantara (PPN) Karangantu, Kota Serang.

\section{METODE PENELITIAN}

Penelitian ini menggunakan metode experimental fishing. Satuan percobaan penelitian ini adalah bagan perahu dengan lampu bawah air sebagai objek yang diteliti dan bagan perahu tanpa menggunakan lampu bawah air sebagai kontrol. Penelitian diasumsikan bahwa daerah penyebaran ikan dan faktor yang mempengaruhi penyebaran ikan dianggap sama. Hal ini diperkuat oleh Kumajas (2015) menyatakan bahwa, penelitian yang bersifat eksperimental yaitu dengan sengaja mengusahakan timbulnya variabel-variabel yang selanjutnya dikontrol untuk dilihat pengaruhnya terhadap obyek penelitian, dengan studi kasus sebagai dasar penelitian yakni mempelajari suatu kasus tertentu pada objek terbatas. Penelitian ini dilaksanakan pada bulan Maret 2018 di Pelabuhan Perikanan Nusantara (PPN) Karangantu, Kota Serang

Metode pengambilan sampel (sampling) merupakan faktor penentu dalam melakukan penelitian. Sampling dilakukan dengan dua perlakuan yaitu bagan perahu dengan lampu bawah air dan bagan perahu tanpa lampu bawah air atau hanya menggunakan lampu permukaan. Data sampel yang diambil adalah berat total hasil tangkapan per jenis ikan yang ditimbang di TPI Karangantu. Pengoperasian bagan perahu masing-masing dilakukan selama 10 trip dengan lama waktu pengoperasian per trip yaitu 10 jam. Menurut Rudin et al. (2017), penelitian dilakukan dengan menggunakan metode experimental fishing yaitu mengikuti kegiatan penangkapan ikan dengan 2 bagan tancap yang berbeda di Perairan Teluk Banten. Pemilihan 2 bagan tancap ini dilakukan berdasarkan jarak jauh dan dekat fishing ground dari fishing base. Operasi penangkapan ikan dilakukan di bagan selama 20 malam di lokasi yang berbeda. Bagan satu dan dua dilakukan selama 10 malam sebelum dan sesudah bulan terang. Kegiatan penangkapan ikan dimulai dari jam 18.00 WIB sampai jam 05.00 WIB.

Penelitian ini menggunakan lampu bawah air yang bertujuan untuk mengumpulkan ikan dengan asumsi tidak ada pembiasan cahaya dari udara ke air seperti saat menggunakan lampu permukaan. Intensitas cahaya lampu bawah air diukur dengan jarak 1 meter dari sumber cahaya secara horizontal menggunakan lux meter memperoleh hasil 198 lux di darat. Intensitas cahaya akan menurun apabila cahaya masuk dalam perairan. Penurunan intensitas cahaya lampu bawah air saat penelitan didapatkan 109 lux di bawah permukaan air laut. Menurut Setiawan et al. (2015), dari ketiga jenis medium perantara dapat dilihat penurunan nilai intensitas cahaya masing-masing medium perantara saat di udara mengalami penurunan $0,86 \mathrm{lux} / \mathrm{cm}$, pada air tawar mengalami penurunan $0,886 \mathrm{lux} / \mathrm{cm}$ dan pada air laut mengalami penurunan 0,89 lux $/ \mathrm{cm}$. Penurunan terbesar terdapat pada air laut karena dalam laut cahaya mengalami penghamburan yang besar oleh material pada air laut lebih pekat dibandingkan air tawar dan udara. Lampu bawah air adalah lampu yang dimasukkan ke dalam air untuk menarik ikan berkumpul pada catchable area agar penangkapan lebih efektif dan efisien. Lampu bawah air harus dibuat kedap air agar air tidak masuk pada rangkaian lampu

(c) Copyright by Saintek Perikanan (Indonesian Journal of Fisheries Science and Technology), ISSN : 1858-4748 
sehingga umur pemakaian lampu dapat bertahan lama. Survei dilakukan sebelum pembuatan untuk menentukan material dan ukuran lampu bawah air yang akan digunakan, salah satunya menentukan jenis lampu yang digunakan dengan memperhatikan intensitas dan sumber tenaganya. Menurut Sihombing (2012), merancang lampu bawah air dengan memperhatikan intensitas cahaya yang dihasilkan dapat memecahkan masalah kurang maksimalnya hasil tangkapan bagan. Cahaya lampu alternatif ini diharapkan dapat membuat ikan-ikan yang bersifat fototaksis positif terfokus di atas jaring, sehingga memperoleh hasil tangkapan yang lebih banyak dari lampu bagan. Konstruksi lampu bawah air dapat dilihat pada gambar berikut.

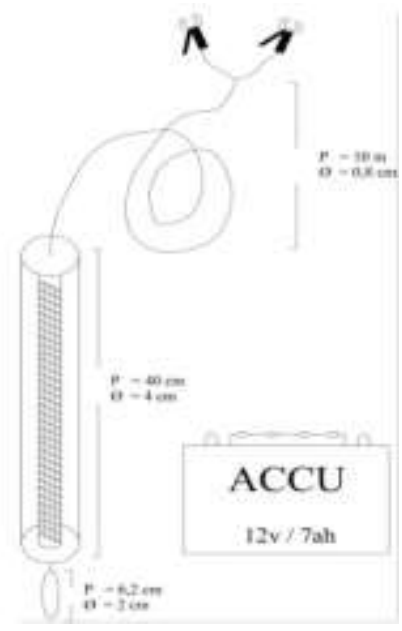

Gambar 1. Desain Lampu Bawah Air

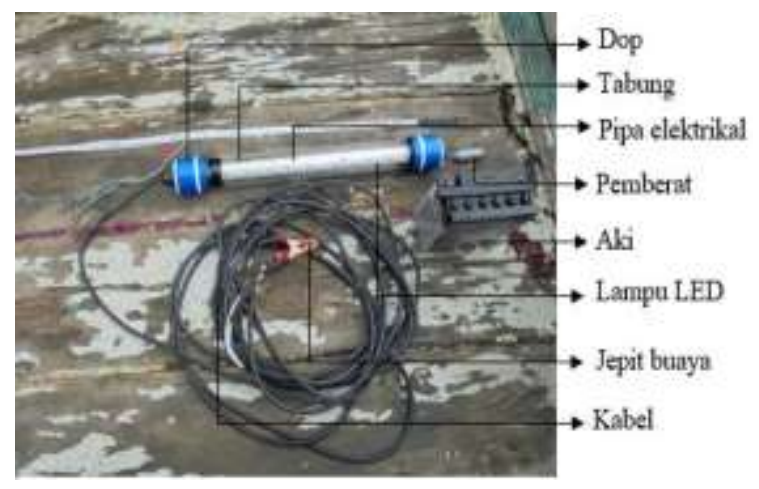

Gambar 2. Lampu Bawah Air.

Konstruksi lampu bawah air pada saat penelitian adalah sebagai berikut:

1. Dop berbahan PVC (polyvinyl chloride) dengan panjang 5 $\mathrm{cm}$ dan diameter $5,5 \mathrm{~cm}$.

2. Tabung berbahan akrilik dengan panjang $40 \mathrm{~cm}$, diameter 4 $\mathrm{cm}$ dan tebal $0,5 \mathrm{~cm}$.

3. Pipa elektrikal berbahan PVC dengan panjang $35 \mathrm{~cm}$, diameter 2,5 $\mathrm{cm}$ dan tebal $0,1 \mathrm{~cm}$.

4. Pemberat berbahan timah dengan panjang $6,2 \mathrm{~cm}$, diameter $2 \mathrm{~cm}$ dan berat 270 gram.

5. Aki menggunakan aki basah dengan tegangan 12 volt, kuat arus 7 ah dan berat $1,8 \mathrm{~kg}$.

6. Lampu LED (Light Emitting Diode) menggunakan jenis strip $60 \mathrm{~cm}$ dengan daya 8 watt, tegangan 12 volt dan warna cahaya putih
7. Jepit buaya dibedakan dengan warna merah (+) dan hitam (-). Panjang jepit yaitu $8 \mathrm{~cm}$ dan bukaan mulut jepit $3 \mathrm{~cm}$.

8. Jenis kabel yang digunakan adalah NYYHY. Kabel memiliki panjang $10 \mathrm{~m}$ dan diameter $0,8 \mathrm{~cm}$.

Penggunaan intensitas cahaya yang tepat memudahkan ikan berkumpul di catchable area. Lampu LED dipilih untuk penggunaan lampu bawah air karena sumber tenaga dan konsumsi bahan bakar lebih hemat dibandingkan lampu mercury, hal tersebut dikarenakan daya dan tegangan lampu LED lebih kecil. LED adalah komponen elektronik yang dapat memancarkan cahaya monokromatik ketika diberikan tegangan listrik. Dampak lampu LED terhadap lingkungan jauh lebih aman karena tidak mengandung logam berat yang dapat menimbulkan pencemaran lingkungan. Lampu LED yang digunakan saat penelitian berwarna putih karena fish target dari bagan perahu yang merupakan ikan Teri dan Cumi yang dapat merespon lampu tersebut dengan cepat dan lama berada di sekitar catchable area. Lampu LED memiliki daya 8 watt dan tegangan 12 volt sehingga tidak banyak menghabiskan energi listrik. Lampu LED menggunakan jenis strip $60 \mathrm{~cm}$ karena rangkaiannya seri sehingga menghasilkan cahaya lebih optimal. Adanya asumsi, semakin besar intensitas cahaya akan meningkatkan hasil tangkapan mendorong nelayan menggunakan lampu dalam jumlah banyak dan konsumsi energi yang tinggi, sedangkan setiap jenis ikan memiliki kemampuan adaptasi dan respon berbeda terhadap intensitas cahaya. Menurut Susanto et al. (2017), teknologi lampu light emitting diode (LED) merupakan jawaban terhadap kebutuhan fishing lamp ideal untuk aktivitas penangkapan ikan. Lampu LED dapat diproduksi sesuai dengan panjang gelombang dan level energi tertentu sehingga pengunaanya lebih efisien. Ikan Teri (Stolephorus sp.) merupakan komoditas perikanan ekonomis penting yang ditangkap menggunakan teknologi penangkapan dengan alat bantu cahaya, seperti bagan tancap, bagan apung, bagan perahu dan payang. Penggunaan cahaya pada penangkapan ikan teri mengalami perkembangan pesat dengan jenis dan kekuatan lampu yang beragam. Namun sebagian besar lampu yang digunakan adalah berwarna putih dari jenis fluorescent karena harganya terjangkau, mudah diperoleh dan cukup efektif untuk menarik perhatian ikan teri.

Lampu bawah air diletakkan pada sisi kiri kapal yang mana terdapat daun bagan sebagai tempat tertangkapnya ikan. Penempatan lampu bawah air dapat dilihat pada gambar berikut.

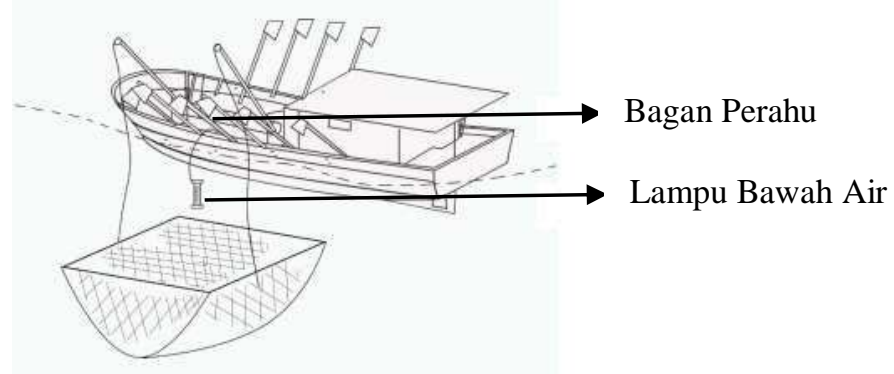

Gambar 3. Bagan Perahu Menggunakan Lampu Bawah Air.

Lampu bawah air dipasang pada rangka bambu yang juga sebagai tempat tiang-tiang lampu dipasang. Posis

(c) Copyright by Saintek Perikanan (Indonesian Journal of Fisheries Science and Technology), ISSN : 1858-4748 
pengoperasian lampu bawah air diletakkan di dekat bagian rangka bambu yang sejajar dengan kapal agar ikan-ikan berkumpul pada catchable area bagan. Lampu bawah air dioperasikan saat immersing bagan perahu. Setelah jaring diturunkan pada perairan, lampu-lampu bagan dinyalakan, kemudian lampu bawah air diturunkan pada perairan dan dinyalakan. Lampu bagan dimatikan secara bertahap hingga menyisakan lampu fokus pada bagan, lampu bawah air dimatikan. Kemudian jaring diangkat agar ikan tidak meloloskan diri dari area jaring. Setelah hasil tangkapan dinaikkan ke atas kapal, bagan perahu melakukan setting kembali begitu juga lampu bawah air dioperasikan kembali sama seperti pengoperasian sebelumnya.

Analisis data menggunakan aplikasi IBM SPSS Statistics 25.0 Lisense Authorization Wizard. Pengolahan data menggunakan uji normalitas, uji homogenitas dan uji t. Pengambilan keputusan dengan perbandingan terhadap nilai signifikansi $=0,05$. Jika nilai signifikansi $>0,05$ maka, $\mathrm{H} 0$ diterima dan $\mathrm{H} 1$ ditolak. Jika nilai signifikansi $<0,05$ maka, $\mathrm{H} 0$ ditolak dan $\mathrm{H} 1$ diterima. Hipotesis pada penelitian ini adalah sebagai berikut:

1. H0: Tidak terdapat pengaruh antara lampu bawah air (underwater lamp) dengan hasil tangkapan pada bagan perahu (boat lift net); dan

2. H1: Terdapat pengaruh antara lampu bawah air (underwater lamp) dengan hasil tangkapan pada bagan perahu (boat lift net).

\section{HASIL DAN PEMBAHASAN}

Letak astronomis PPN Karangantu berada pada koordinat antara $5^{\circ} 50^{\prime}$ LS sampai $6^{\circ} 3^{\prime}$ LS dan $106^{\circ} 9^{\prime} \mathrm{BT}$ sampai $106^{\circ} 11$ ' BT, secara administratif memiliki batasanbatasan sebagai berikut:

1. Sebelah Utara berbatasan dengan Laut Jawa;

2. Sebelah Selatan berbatasan dengan Desa Margaluyu dan Desa Kasunyatan;

3. Sebelah Barat berbatasan dengan Desa Pamengkang; serta

4. Sebelah Timur berbatasan dengan Desa Sawah Luhur.

PPN Karangantu yang mempunyai luas 30 ha, terletak di Desa Banten, Kecamatan Kasemen, Kota Serang, Provinsi Banten. PPN Karangantu memiliki satu Tempat Pelelangan Ikan yang masih berfungsi sebagai sarana aktifitas dan bertemunya nelayan dengan bakul. Hal ini diperkuat oleh Apriani et al. (2013) yang menyatakan bahwa, Pelabuhan Perikanan Nusantara Karangantu merupakan salah satu pusat aktivitas perikanan tangkap di Provinsi Banten dengan produktivitas yang tinggi. Ikan yang didaratkan tidak hanya didistribusikan ke wilayah Provinsi Banten, namun juga dijual ke Jakarta dan Lampung.

\section{Hasil Tangkapan}

Berdasarkan penelitian yang telah dilakukan, hasil tangkapan bagan perahu dengan maupun tanpa lampu bawah air didapatkan komposisi hasil tangkapan yang tidak jauh berbeda baik dari total hasil tangkapan maupun jenis ikan. Komposisi hasil tangkapan bagan perahu tanpa lampu bawah air dapat dilihat pada gambar 4.

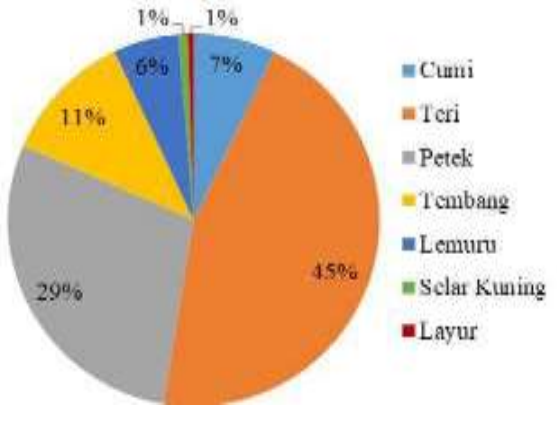

Gambar 4. Diagram Komposisi Hasil Tangkapan Bagan Perahu Tanpa Lampu Bawah Air.

Berdasarkan penelitian yang dilakukan bagan perahu tanpa menggunakan lampu bawah air beroperasi sebanyak 10 trip yang mana nelayan bagan perahu melakukan satu trip pengoperasian yaitu satu hari melaut atau one day fishing. Hasil tangkapan yang diperoleh ada 7 jenis ikan yaitu Cumicumi (Loligo sp.), Teri (Stolephorus sp.) sebagai hasil tangkapan utama. Petek (Leiognathus sp.), Tembang (Sardinella sp.), Lemuru (Amblygaster sirm), Selar Kuning (Selaroides leptolepis) dan Layur (Lepturacanthus savala) sebagai hasil tangkapan sampingan. Komposisi hasil tangkapan dari bagan perahu tanpa menggunakan lampu bawah air yaitu Cumi-cumi dengan persentase sebesar $7 \%$, Teri sebesar $45 \%$, Petek sebesar 29\%, Tembang sebesar 11\%, Lemuru sebesar $6 \%$, Selar Kuning sebesar 1\% dan Layur sebesar 1\%. Hasil tangkapan paling banyak adalah ikan Teri dengan persentase $45 \%$ dan paling sedikit adalah ikan Layur dengan persentase $1 \%$.

Bagan perahu menggunakan lampu bawah air juga beroperasi sebanyak 10 trip sebagai pengulangan. Komposisi hasil tangkapan bagan perahu dengan lampu bawah air dapat dilihat pada gambar berikut.

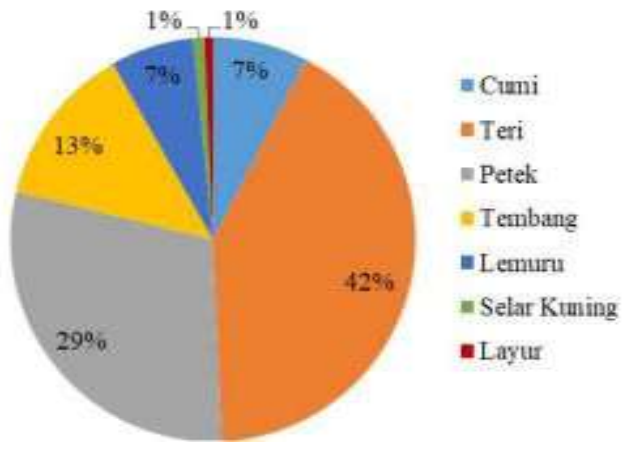

Gambar 5. Diagram Hasil Tangkapan Bagan Perahu Dengan Lampu Bawah Air

Hasil tangkapan sama dengan bagan perahu tanpa lampu bawah air terdapat 7 jenis ikan yaitu Cumi-cumi (Loligo sp.), Teri (Stolephorus sp.) sebagai hasil tangkapan utama. Petek (Leiognathus sp.), Tembang (Sardinella sp.), Lemuru (Amblygaster sirm), Selar Kuning (Selaroides leptolepis) dan Layur (Lepturacanthus savala) sebagai hasil tangkapan sampingan. Komposisi hasil tangkapan dari bagan perahu dengan menggunakan lampu bawah air yaitu Cumi-cumi

(ㄷ) Copyright by Saintek Perikanan (Indonesian Journal of Fisheries Science and Technology), ISSN : 1858-4748 
dengan persentase sebesar $7 \%$, Teri sebesar $42 \%$, Petek sebesar $29 \%$, Tembang sebesar 13\%, Lemuru sebesar 7\%, Selar Kuning sebesar $1 \%$ dan Layur sebesar 1\%. Hasil tangkapan yang diperoleh juga paling banyak ikan Teri dengan persentase $42 \%$ dan paling sedikit adalah ikan Layur dengan persentase $1 \%$.

Berdasarkan data hasil penelitian yang telah dilakukan, perbandingan total hasil tangkapan bagan perahu (boat lift net) dengan lampu bawah air (underwater lamp) dan bagan perahu (boat lift net) tanpa lampu bawah air (underwater lamp) dapat dilihat pada gambar 5.

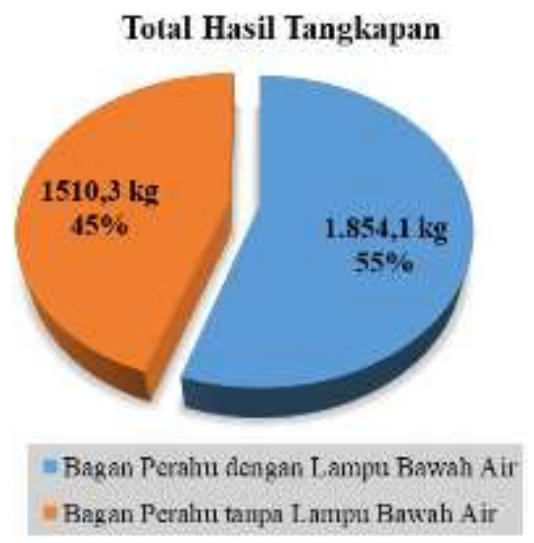

Gambar 5. Perbandingan Hasil Tangkapan Bagan Perahu dengan dan tanpa Lampu Bawah Air.

Berdasarkan grafik di atas total hasil tangkapan seluruh trip bagan perahu dengan lampu bawah air adalah $1.854,1 \mathrm{~kg}$ dan total hasil tangkapan seluruh trip bagan perahu tanpa lampu bawah air atau hanya dengan lampu permukaan adalah 1.510,3 kg. Hasil persentase yang diperoleh bagan perahu dengan lampu bawah air adalah $55 \%$ dan bagan perahu tanpa lampu bawah air adalah $45 \%$ menunjukkan bahwa hasil tangkapan bagan perahu dengan lampu bawah air lebih banyak dibanding bagan perahu tanpa lampu bawah air. Selisih perbedaan hasil tangkapan setiap trip yaitu trip 1 sebesar 33,4 $\mathrm{kg}$, trip 2 sebesar $38,9 \mathrm{~kg}$, trip 3 sebesar $31,1 \mathrm{~kg}$, trip 4 sebesar $41,1 \mathrm{~kg}$, trip 5 sebesar $28,8 \mathrm{~kg}$, trip 6 sebesar $30,5 \mathrm{~kg}$, trip 7 sebesar $35,4 \mathrm{~kg}$, trip 8 sebesar $34,3 \mathrm{~kg}$, trip 9 sebesar $38,7 \mathrm{~kg}$ dan trip 10 sebesar $31,6 \mathrm{~kg}$. Total hasil tangkapan menunjukkan terdapat perbedaan nyata. Hal ini diperkuat oleh Sihombing (2012) yang menyatakan bahwa, operasi penangkapan ikan dengan bagan yang menggunakan lampu bawah air dapat meningkatkan reaksi fototaksis positif ikan sehingga hasil tangkapan yang diperoleh juga meningkat. Peningkatan yang diperoleh dapat mencapai $100 \%$ dari hasil tangkapan biasanya (hanya dengan lampu bagan).

\section{Pembahasan}

Bagan perahu di PPN Karangantu menangkap ikan Teri (Stolephorus sp.) dan Cumi-cumi (Loligo sp.) sebagai hasil tangkapan utama dan ikan lainnya yang tidak sengaja tertangkap sebagai hasil tangkapan sampingan yaitu Petek (Leiognathus sp.), Tembang (Sardinella sp.), Lemuru (Amblygaster sirm), Selar Kuning (Selaroides leptolepi) dan Layur (Lepturacanthus savala). Ikan Teri mendominasi penangkapan bagan perahu dengan dan tanpa lampu bawah air karena ikan Teri tertarik dengan cahaya lampu bagan maupun dengan lampu bawah air dan pengoperasian bagan perahu dilakukan saat musim puncak ikan Teri. Ikan Layur sangat sedikit pada penangkapan bagan perahu dengan dan tanpa lampu bawah air karena ikan Layur tidak agresif sehingga kurang tertarik dengan adanya sumber makanan di sekitar bagan, aktifitas yang relatif rendah menyebabkan gerak ruaya tidak terlalu jauh dan membentuk gerombolan tidak terlalu besar.

Ikan Teri (Stolephorus sp.) merupakan fish target bagan perahu karena jumlah hasil tangkapannya selalu mendominasi setiap fishing trip. Ikan Teri pada bagan perahu dengan lampu bawah air lebih banyak daripada bagan perahu tanpa lampu bawah air. Ikan teri termasuk dalam jenis ikan pelagis kecil fototaksis positif. Ikan teri lebih sering berenang secara bergerombol (schooling). Hal ini diperkuat oleh Susanto et al. (2017) yang menyatakan bahwa, ikan Teri (Stolephorus sp.) adalah komoditas perikanan ekonomis penting yang ditangkap menggunakan teknologi penangkapan dengan alat bantu cahaya, seperti bagan tancap, bagan apung, bagan perahu dan payang. Penggunaan cahaya pada penangkapan ikan teri mengalami perkembangan pesat dengan jenis dan kekuatan lampu yang beragam. Hal ini juga diperkuat oleh Effendy (2005) dalam Nelwan et al. (2015) menyatakan bahwa, ikan Teri merupakan jenis ikan yang responsif terhadap cahaya, sehingga ketertarikan terhadap cahaya mengakibatkan ikan Teri banyak terkonsentrasi di catchable area bagan perahu. Perilaku tersebut menyebabkan peluang tertangkapnya ikan Teri lebih banyak dibanding ikan jenis lainnya.

Cumi-cumi (Loligo sp.) juga fish target bagan perahu karena harganya lebih mahal dibanding ikan jenis lain. Cumicumi pada bagan perahu dengan lampu bawah air lebih banyak dibandingkan bagan perahu tanpa lampu bawah air. Cumi-cumi juga bersifat fototaksis positif. Aktifitas Cumi-cumi pada malam hingga pagi hari mendekati area terang untuk mencari makan. Hal ini diperkuat oleh Febrianto et al. (2017) yang menyatakan bahwa, Cumi-cumi tergolong hewan neuritik yang sebarannya dari lapisan permukaan sampai kedalaman tertentu. Hidup bergerombol dan tertarik pada cahaya lampu (bersifat fototaksis positif). Salah satu alternatif yang menawarkan solusi terbaik adalah mengetahui pola musim penangkapan Cumi-cumi. Musim Cumi-cumi sangat mempengaruhi produksi tangkapan pada bulan-bulan tertentu sehingga dengan diketahuinya musim Cumi-cumi tersebut, maka pengaturan waktu penangkapan dapat dilakukan lebih efektif dan efisien. Hal ini juga diperkuat oleh Puspito (2012) dalam Ahmad et al (2013) menyatakan bahwa, aktivitas makan organisme predator termasuk Cumi-cumi mengalami peningkatan antara pukul 01.00-04.00 WIB. Kondisi Cumi-cumi yang sedang lapar akan lebih mudah dan cepat merespon sumber cahaya yang berada di perairan.

Beberapa ikan jenis lain yang tertangkap bagan perahu yaitu Petek (Leiognathus sp.), Tembang (Sardinella sp.), Lemuru (Amblygaster sirm), Selar Kuning (Selaroides leptolepi) dan Layur (Lepturacanthus savala). Ikan-ikan tersebut sebagai hasil tangkapan sampingan (bycatch). Bycatch bagan perahu dengan lampu bawah air juga lebih banyak daripada bagan perahu tanpa lampu bawah air. Adanya bycatch disebabkan karena sifat predator. Pengoperasian bagan menimbulkan peristiwa rantai makanan berupa ikan-ikan kecil menjadi sumber makanan bagi ikan-ikan yang lebih besar. Hal ini diperkuat oleh Sudirman dan Mallawa (2004) yang menyatakan bahwa, adanya cahaya merupakan suatu indikasi adanya makanan. Adanya cahaya maka plankton dan ikan-ikan kecil berkumpul dengan tujuan feeding. Beberapa jenis ikan

(C) Copyright by Saintek Perikanan (Indonesian Journal of Fisheries Science and Technology), ISSN : 1858-4748 
yang termasuk dalam kategori ini seperti ikan Tenggiri, Cendro, Petek, Tembang dan ikan-ikan lain juga berkumpul. Data diperoleh dari 10 trip pada bagan perahu dengan lampu bawah air dan bagan perahu tanpa lampu bawah air. Data hasil tangkapan yang telah diperoleh dianalisis menggunakan uji statistik parametrik Shapiro-Wilk antara lain uji normalitas, uji homogenitas dan uji t.

1. Uji Normalitas

Nilai signifikansi dari kedua data masing-masing yaitu 0,14 dan 0,219. Data tersebut menunjukan nilaicsignifikansi > 0,05 sehingga dapat diambil keputusan bahwa kedua data tersebut terdistribusi normal.

2. Uji Homogenitas

Nilai signifikansi yang diperoleh dari data penelitian adalah 0,972 . Data tersebut menunjukan nilai signifikansi $>0,05$ sehingga dapat diambil keputusan bahwa varian data tersebut adalah sama (homogen).

3. Uji T

Berdasarkan data penelitian diperoleh nilai signifikansi sig.(2 tailed) adalah 0,019, maka nilai signifikansi 0,05 sehingga diambil keputusan bahwa H0 ditolak dan H1 diterima, artinya terdapat pengaruh antara lampu bawah air (underwater lamp) dengan hasil tangkapan pada bagan perahu (boat lift net).

Lampu bawah air menggunakan LED memiliki tingkat efisiensi energi yang tinggi dibandingkan lampu mercury. Menurut Setiawan et al. (2015), LED (Light Emitting Diode) adalah semikonduktor yang memancarkan cahaya monokromatik ketika diberi tegangan maju. Keunggulan teknologi LED antara lain:

1. Intensitas dan terang yang tinggi;

2. Efisiensi tinggi;

3. Kebutuhan tegangan dan arus yang rendah;

4. Sangat handal (tahan terhadap goncangan dan getaran);

5. Tidak memancarkan sinar UV (Ultraviolet); dan

6. Mudah dikontrol dan diprogram.

Pengoperasian lampu bawah air sangat dipengaruhi oleh faktor alat, lingkungan perairan dan respon ikan. Berdasarkan penelitian yang telah dilakukan jenis ikan hasil tangkapan bagan perahu dengan dan tanpa lampu bawah air secara keseluruhan adalah sama. Pengaruh penggunaan lampu bawah air pada bagan perahu yaitu pada perbedaan berat total hasil tangkapan. Total hasil tangkapan seluruh fishing trip lebih banyak bagan perahu dengan lampu bawah air. Hal ini diperkuat oleh Brown et al. (2013) menyatakan bahwa, hasil tangkapan bagan yang menggunakan Lampu Celup Bawah Air lebih tinggi dibandingkan dari bagan yang menggunakan lampu petromaks. Hasil tangkapan bagan tergantung pada tingkah laku spesies ikan. Jenis ikan yang tertarik secara langsung sering disebut fototaksis positif, jika ada di sekitar area penangkapan yang terang. Jenis ikan yang tidak suka dengan cahaya tetapi kehadirannya pada area penangkapan karena kehadiran mangsanya di area penangkapan.

Berdasarkan penelitian yang telah dilakukan, hasil tangkapan lebih banyak pada bagan perahu dengan menggunakan lampu bawah air dianggap keberadaannya membawa pengaruh dengan meningkatkan keberadaan ikan disekitar bagan sehingga hasil tangkapan meningkat. Ikan mendekati cahaya disebut fototaksis positif. Sifat fototaksis erat kaitannya dengan sel fotoreseptor retina ikan. Cumi-cumi dan ikan Teri merupakan target penangkapan bagan perahu adalah ikan yang bersifat fototaksis positif. Pencahayaan lampu bawah air lebih maksimal dan efisien dibandingkan lampu permukaan karena tidak adanya pembiasan dan pemantulan cahaya, membuat target tangkapan berupa Cumi-cumi dan ikan Teri yang berenang secara bergerombol lebih banyak mendekat ke catchable area bagan. Hasil tangkapan bagan perahu dengan lampu bawah air dominan ikan pelagis karena memiliki sel kon yang padat. Sel kon untuk penglihatan cahaya terang (fotopik) dan sel rod untuk penglihatan samar (skotopik). Menurut Francke et al. (2014) dalam Susanto et al. (2017), setiap spesies ikan memiliki kemampuan respon berbeda terhadap rangsangan cahaya lampu yang diterima. Faktor utama yang mempengaruhi kemampuan respon ikan terhadap cahaya adalah susunan sel fotoreseptor pada retina mata. Semakin kompleks dan padat jenis dan komposisi sel kon yang dimiliki, maka kemampuan adaptasi dan responnya terhadap cahaya semakin baik.

\section{KESIMPULAN}

Kesimpulan yang dapat diambil dari hasil penelitian yang telah dilakukan adalah sebagai berikut:

1. Hasil penelitian menunjukkan bahwa hasil tangkapan bagan perahu dengan lampu bawah air lebih banyak dibandingkan bagan perahu tanpa lampu bawah air, sehingga terdapat pengaruh antara lampu bawah air dengan hasil tangkapan pada bagan perahu.

2. Hasil tangkapan utama bagan perahu adalah Teri (Stolephorus sp.) dan Cumi-cumi (Loligo sp.). Hasil tangkapan sampingan antara lain Petek (Leiognathus sp.), Tembang (Sardinella sp.), Lemuru (Amblygaster sirm), Selar Kuning (Selaroides leptolepi) dan Layur (Lepturacanthus savala). Komposisi jenis ikan yang tertangkap pada bagan perahu dengan lampu bawah air dan bagan perahu tanpa lampu bawah air adalah sama.

\section{DAFTAR PUSTAKA}

Ahmad, Supriono., Gondo Puspito., M. Fedi A. Sondita dan Roza Yusfiandayani. 2013. Penguatan Cahaya Pada Bagan Menggunakan Reflektor Kerucut Sebagai Upaya Meningkatkan Hasil Tangkapan Cumi-cumi. Marine Fisheries. 4(2): 163 - 173.

Apriani., Ririn Irnawari dan Adi Susanto. 2013. Komposisi Hasil Tangkapan Jaring Silir yang Berbasis di PPN Karangantu Kota Serang Provinsi Banten. Jurnal Ilmu Pertanian dan Perikanan. 2(2): $152-162$

Bahri, Fathul. 2008. Perikanan Bagan Perahu dan Pengembangannya di Perairan Teluk Bima [Skripsi]. Program Studi Pemanfaatan Sumberdaya Perikanan, Fakultas Perikanan dan Ilmu Kelautan, Institut Pertanian Bogor. Bogor.

BBPPI. 2012. Petunjuk Praktis Bagi Nelayan. Cetakan ke-5: Edisi Ke-3.

Brown, Arthur., Isnaniah dan Soraya Domitta. 2013. Perbandingan Hasil Tangkapan Kelong (Lift Net) Menggunakan Lampu Celup Bawah Air (LACUBA)

\footnotetext{
() Copyright by Saintek Perikanan (Indonesian Journal of Fisheries Science and Technology), ISSN : 1858-4748
} 
dan Petromaks di Perairan Desa Kote Kecamatan Singkep Kabupaten Lingga Propinsi Kepulauan Riau. Jurnal Akuatika. 4(2): 149 - 158.

Febrianto, Arif., Domu Simbolon., John Haluan dan Mustaruddin. 2017. Pola Musim Penangkapan Cumicumi di Perairan Luar dan Dalam Daerah Penambangan Timah Kabupaten Bangka Selatan. Marine Fisheries. 8(1): 63 - 71.

Fuad., Sukandar dan Alfan Jauhari. 2016. Pengembangan Lampu Bawah Air Sebagai Alat Bantu pada Bagan Tancap di Desa Tambak Lekok Kecamatan Lekok Pasuruan. Jurnal Kelautan. 9(1): 7 - 11.

Kumajas, Henry James. 2015. Pengaruh Warna Lampu Dalam Air Terhadap Hasil Tangkapan Bagan Perahu di Perairan Bacan Kabupaten Halmahera Selatan. Jurnal LPPM Bidang Sains dan Teknologi. 2(1): $44-61$.

Nelwan, Alfa F.P., M. Yusron Nur Indar dan Muhammad Nur Ihsan. 2015. Analisis Produktivitas Penankapan Bagan Perahu di Perairan Kabupaten Polewali Mandar. Jurnal IPTEKS PSP. 2(4): 345 - 356.

Rahmawati, Epry., Ririn Irnawati dan Ani Rahmawati. 2017. Kelayakan Usaha Bagan Perahu yang Berbasis di Pelabuhan Perikanan Nusantara Karangantu Provinsi Banten. Jurnal Perikanan dan Kelautan. 7(1): 40 - 49.
Rudin, M Johar., Ririn Irnawati dan Ani Rahmawati. 2017. Perbedaan Hasil Tangkapan Bagan Tancap dengan Menggunakan Lampu CFL dan LED Dalam Air (Leda) di Perairan Teluk Banten. Jurnal Perikanan dan Kelautan. 7(2): $167-180$.

Setiawan, Ferdi., Sri Ratna Sulistiyanti dan Ageng Sadnowo. 2015. Analisis Pengaruh Medium Perambatan Terhadap Intensitas Cahaya Lacuba (Lampu Celup Bawah Air). Jurnal Rekayasa dan Teknologi Elektro. 9(1): $21-29$.

Sihombing, Martua Edison. 2012. Pengaruh Intensitas Cahaya Lampu Bawah Air Dengan Senter Light Emitting Diode Pada Reaksi Fototaksis Ikan di Perairan Kepulauan Seribu [Skripsi]. Departemen Fisika, Fakultas Matematika Dan Ilmu Pengetahuan Alam, Institut Pertanian Bogor. Bogor.

Sudirman dan Achmar Mallawa. 2004. Teknik Penangkapan Ikan. Jakarta: Rineka Cipta.

Susanto, Adi., Aristi Dian Purnama Fitri., Yuhelsa Putra., Heri Susanto dan Tuti Alawiyah. 2017. Respons dan Adaptasi Ikan Teri (Stolephorus sp.) Terhadap Lampu Light Emitting Diode (LED). Marine Fisheries. 8(1): $39-49$. 